\title{
CONSENT TO TREATMENT AND OTHER MEDICAL INTERVENTIONS: LEGISLATIVE AND SCIENTIFIC APPROACHES
}

DOI: 10.36740/WLek202012219

\author{
Natalia D. Kogut, Serhii Y. Petriaiev \\ NATIONAL TECHNICAL UNIVERSITY OF UKRAINE"IGOR SIKORSKY KYIV POLYTECHNIC INSTITUTE", KYIV, UKRAINE
}

\begin{abstract}
The aim: To research approaches to maintaining balance between social and personal interests in the sphere of human right to consent to medical interventions. Materials and methods: The research is conducted with help of both general and special juridical methods of investigation. The empirical basis: an international legal acts; domestic laws of EU countries, the USA and other states; courts' decisions; statistics; juridical and medical articles.

Conclusions: Consent to medical interventions is an absolute right of mentally capable adults and restriction of this right is never too necessary for social interest except for limiting measures due to pandemic or psychiatric disorders threaten. Next of kin or guardian has the right to consent for minors or mentally disabled in their best interests.
\end{abstract}

KEY WORDS: consent to treatment; patient's rights; restriction of patient's rights

Wiad Lek. 2020;73(12 p. II):2816-2820

\section{INTRODUCTION}

Right to health and life are amongst the main natural rights of the human being. It is of great importance to come to convergence in the legislation of all democratic states in approaches for respect to human right to life and health. In today's circumstances of globalization and people's travelling, everyone has the right to be aware of his/her basic rights and relevant risks.

According to the main international acts in medical law sphere (Declaration of Lisbon on the rights of the patient [1]; European Charter of Patient's Rights [2]; International Code of Medical Ethics [3], Convention on Human Rights and Biomedicine [4]), every patient has right to information about his/her health; right to informed consent to medical treatment and other medical interventions; right to free choice of the possible methods and measures of treatment. Despite these principles, exists question of maintaining balance between social interests and personal rights. For example, coerced children vaccination, organ donation under presumption of consent, forced sterilization, psychiatric clinic placement by force etc.

\section{THE AIM}

The main goal is to research the main legislative and scientific approaches to the consent to treatment and other medical interventions all over the world and the main conflicts of social and personal interests in medical sphere that have different points on necessity of consent to treatment and medical invasions. Either, we aim to find out the main legal gaps and infringements of human right to consent.

\section{MATERIALS AND METHODS}

The legal basis of the study: The International Covenant on Civil and Political Rights (1966); European Charter of Patient's Rights (2002); Declaration of Lisbon on the rights of the patient (1993); Declaration of Oslo Statement on Therapeutic Abortion (1970); The Convention for the Protection of Human Rights and Dignity of the Human Being with Regard to the Application of Biology and Medicine: Convention on Human Rights and Biomedicine (Ovideo Convention, 1997); International Code of Medical Ethics (1949) and some domestic laws of Spain, Poland, United Kingdom (UK), Ukraine and other countries.

The following methods of scientific research are used in this research: comparative legal method; formal-logical (dogmatic) method; statistical method; methods of analysis and synthesis.

\section{REVIEW AND DISCUSSION}

Health right is highly connected with right to true, entire and correct information about state of patient's health, the diagnosis, methods of treatment, medical prognosis etc. Based on this information, patient may give his consent to treatment, which often calls "informed consent to treatment". Some countries allow physicians to hide such information from both adult and minor patients when they have a reasonable position that it may aggravate their state and worsen the process of treatment and its results (Art. 285 of Civil Code of Ukraine [5]). Taking into account knowledges about placebo effect, getting aware of hard diagnosis usually leads to depression, thus aggravating of 
health. Nevertheless, hiding information about patient's health and methods of treatment leads to breaking one of the main rights of the patient in the medical law - right to consent or disconsent to medical treatment.

A mentally competent adult patient has an absolute right to reject medical treatment or other medical intervention for any reason, doesn't matter rational or irrational, even in case when the decision may lead to his/her death. Sometimes, compulsory medical measures may be avoided of medical interventions and be connected with freedom deprivation. It is very relevant due to Covid-19. In difficult epidemic and pandemic cases states usually implement measures to arrest the spread, however, such measures as quarantine or isolation often conflict with civil liberties [6]. Conrad Nyamutata (2020) admits that "even traditional democratic states mimic authoritarian regimes" [7]. Democratic countries have liabilities under international treaties to use principle of proportionality in applying any kind of liberty-limiting interventions. Such measures shouldn't include forced medical invasions, only some restrictions in movements. Full deprivation of liberty into specialized medical institutions may be applied only under the court's decision (tuberculosis dispensary or psychiatric clinic placement by force).

The International Covenant on Civil and Political Rights (1966) [8], in Art. 9 states that restriction of human freedom in any form is possible only by court's decision. Nevertheless, pre-trial freedom deprivation is being practicing in many countries. However, European Court of Human Rights admits that when person is detained as a result of aggressive behaviour it may be acceptable to apply compulsory hospitalization, but it is necessary to obtain medical conclusion on psychiatric disorder after a proper examination immediately after the deprivation [9]. Not all psychiatric disorders are the basis to apply liberty deprivation but only those, which are combined with a threat to society or patient itself [10].

Patients of psychiatric clinics are deprived of right to sue by themselves after some period of their compulsory hospitalization and also have no right to choose another doctor, clinic or an alternative point of view about the treatment measures. That's because they are presumed to be mentally disordered, but it is also the reason why they often suffer of ill treatment and application of too much of sedative drugs, which poses obstacle to their recovery.

There are special norms for consent to treatment concerning children under the domestic law. The most commonly used age with absolute capability of making decisions of health care is 18 years as in most European Union (EU) countries and some Canadian provinces. Some states use an alternative demarcations, such as 16 years (eg. Ukraine, Scotland) or 19 years (eg. a few Canadian provinces: British Columbia, Labrador and others). Various European countries have adopted a system in which healthcare specialists have competence to evaluate maturity of the minor on a case-by-case basis [11], without specification of the age. In other states additional conditions about consent to some definite medical measures (eg. in Quebec
(Canada) consent can be given by patient of 14 years but parents should be informed about definite kinds of medical procedures). An opposite example, countries, which demand dual consent from both parent and the minor (Poland) [12]. In most countries, it is enough for doctors to obtain consent for definite medical treatment from one of the parents, but in case of disagreement physician may ask court for consent if such measures are not urgent. In Spain, the opinion of the minor should also be taken into account at least from the age of 12 . It is preferably when domestic law anticipates requirement to inform parents about all serious risks and interventions about minor of any age and to take into account their opinion.

In Ukraine plenty of medical invasions may be done for minors even from 14 years old, for example, an abortion. Nevertheless, medicals have no obligation to inform parents about such medical invasion. That's a negative approach, because parents still bear responsibility for health and welfare of their children. On the other hand, in some countries parents or guardians have the right to give consent for sterilization of minors and incapable adults despite of their volition. In our opinion, such decisions should be adjudicated only by courts in cases of serious psychiatric deceases; such procedure shouldn't be applicable for minors at all. The same position is supported by other scientists (V. Iemelianenko, A. Gornostay, A. Ivantsova, 2019) [13].

United Nations Committee on Human Rights recognizes forced sterilization as a kind of torture and ill-treatment, also any other medical treatment or intervention without person's consent is a violation of human rights. However, the United States, Russia and China excluded themselves from the jurisdiction of the International Criminal Court. For example, in the USA court's decisions with compulsory sterilization still happen. Failure in paying money for raising children because of lack of profit became the ground for court's orders on forced sterilization in Virginia and Ohio in 2014. [14]. EU accepted that forced sterilization can't be a kind of punishment, but in our opinion forced sterilization may in some cases be a kind of prevention to giving birth to badly sick infants with hereditary deceases or disabilities (persons with hereditary hard psychiatric sicknesses and chronic alcohol and drug addicted persons) after obtaining both guardians' and court's permission.

Forced abortion isn't allowed even in cases when there is a medical reason, because adult capable woman has the right to decide and the possibility to take care of afflicted child, on the contrary incapable adults wouldn't be able to do so. Surely, only intellectual disability may be the ground for forced abortion. Still it is better to apply one medical invasion - sterilization then every time to operate abortions to intellectually disabled women. A horrible practice was recently leading and still happens in China, for example Feng Jianmei was forcibly made an abort to 7-month old fetus because of failure of paying fine for breaching one-child policy (June 2012) [15].

Another question appears from what period fetus has the right to life. Legislation doesn't give strict answer to this ques- 
tion. However, there is a maximum term in which woman has the right to apply for an abortion without any medical reason. The most spread time-limit in EU is 12 months of pregnancy (Austria, Belgium, Bulgaria, Czech Republic, France, Greece, Hungary, Italy, Latvia, Lithuania, Luxemburg, Poland, Portugal, Slovakia). There are also other limits like in Sweden - 18 months, in Germany - 22 months, in Netherlands and UK - 24 months. Currently, UK is in the process of adoption the limits for abortions in line with the majority of EU countries. It's worth to say that even in the term of 12 weeks of pregnancy fetus is a formed human creature with heart beating and electrical brainwaves. Some countries recognize right to life of fetus, for example, in Ukraine artificial abortion may be performed under medical grounds only till 24 weeks of pregnancy, the third trimester is prohibited for abortion even under threaten to the woman's life. This is quite reasonable, because an abortion at such a late term is similar with childbirth and the vitality of such babies is quite high, so it may be premature childbirth induced artificially, thus it is a criminal offence to mortify a newborn.

Question about abortions and "fetal rights" should be regulated in the legislation. Joanna N. Erdman (2017) admitted: "rather than eliminate the moral and ethical questions of later abortion, the law reassigns them to physicians in the guise of professional judgment" [16]. Physicians set their own conditions on the legislative norms, which merely allow abortion until the gestation of 24 weeks, but do not require its availability. Late abortion is available only for women with hard fetal or women's diagnosis, but inappropriate age and financial constraint may also be considered.

Under the European Convention on Human Rights (Art. 8), the European Court recognizes that regulation of abortion and decision to become a parent should not engage a woman's right for private and family life [17]. Under the Declaration of Oslo Statement on Therapeutic Abortion (1970) decision on abortion is to be made by women themselves without coerce and permission of husband or father of the fetus, because pregnancy and childbirth are connected with woman's right to patient autonomy and right to privacy [18].

One of the most ambiguous question connected with parents' consent to medical interventions and social interest is the problem of coerced vaccination. In certain countries vaccination is a coercive measure of infectious diseases' prevention (Australia, Belgium, Italy, Serbia, Slovenia, the USA, France, Ukraine, Russia). At the same time, in all EU countries and in Canada vaccination is only recommended, but not coerced [19]. Legislative norms of those countries which enshrined coerced vaccination vary for many cases: 1) amount of compulsory vaccines (Russia and Ukraine have the biggest amount of mandatory vaccines - more then 10); 2) fines for evasion of vaccination; 3 ) range of reasons of exemption of the vaccination. For example, in some states of the USA there is an exceptions which allow to refuse vaccination due to medical, religious or ideological reasons [20], but mainly countries with the conception of coerced vaccination allow only medical reasons for vaccination rejection.
In our opinion, there is a difference between coerced and forced vaccination, disconsent to coerced one provides some negative consequences to parents like fines or/and impossibility for child to attend preschool or school institutions. The other situation with forced vaccination which performs without parent's consent and even without make them informed about such medical intervention which was usual in the USSR. Herd immunity is of great importance, nevertheless, immunized people have no threat from those who are not immunized, that's the essence of vaccination. So, should be vaccination imposed for safe of those part of society who refuse it? The balance is between the artificial threat to the children's life and their health (vaccine's aftereffect of death and different prolonged health issues) and potential possibility to obtain some infectious disease and transmit it to others. We shouldn't forget about possibility of pharmaceutical lobby and insufficient researches in this sphere which may influence on enacting a coercive vaccination policy. All states anticipate a compensation for adverse effects from the vaccination, but the trouble is to prove connection between the vaccination and death or any health afflictions. Nevertheless, even low percentage of proved deaths as a result of vaccination doesn't give an ethical right to forced vaccination. There are also plenty other adverse prolonged effects like paresis after polio vaccines. Age and sex have also to be considered, eg. diphtheria-tetanus pertussis vaccines are associated with higher mortality of females [21].

The other question connected with conflict of social interests and right to consent is an organ removal for transplantation. The first trouble is how to regulate accurate diagnosis of human death. For example, in accordance with Art. 2 and 15 of the Venezuelan Law "On transplantation of organs and anatomical materials of the person" death should be established on the basis of traditional criteria of clinical death (cardiac and respiratory arrest, absence of reaction to external stimuli) or complete cessation of the electrical activity of the brain for 30 minutes (people with vegetative state whose vitality are maintained artificially) [22]. Under the Non-heart beating organ donation protocols in the USA (so-called controlled NHBD protocols) when the ventilator is stopped and heartbeat and breathing stops transplant team has the right to remove the organs for just 2 to 5 minutes after the person was declared dead. That's despite the fact that Dr. Michael DeVita, one of the inventors of NHBD protocol, has admitted the possibility of brain recovery for at least 15 minutes [23].

According to Mental Capacity Act of UK, 2003 [24] not only consent of next of kin but either court's decision is needed in case of withdrawal of nutrition and hydration from a person who's in the permanent vegetative state or minimally conscious state. Ronald E. Cranford (2002) persists that no one can say for sure at what point the transient state becomes permanent one. But minimally conscious state shouldn't be the ground for withdrawal of nutrition and ventilator for at least statistically defined period of time when vegetative state becomes permanent: 3 months for patients with anoxicischemic injuries of the brain and 12 
months for patients with traumatic injuries. [25]. But this scientifically defined periods of time are not enshrined in the legislation. To minimize a possibility of acting not in best interests of the patient Ovideo Convention states that there is to be no financial gain from the organ donation for relatives/guardians of the donors.

There are also legislative propositions to allow to take off organs before the statement of the death in case of withdrawal of the ventilator in so-called "hopeless" patients' cases when they still have a heart-beating and breathing after ventilator withdrawal, because it is presumed that they will die in any case, but after some time of dying their organs will be unsuitable for donation [26]. Juridical question of obtaining consent to organ transplantation from next of kin may be solved before the declaration of death or after it. Legislation doesn't anticipate compulsory norms to obtain consent to other actions to support organs in optimal state like catheterization and heart-lung bypass etc. Logically, that such pre-mortal interventions are not ethical, since they have no benefit to the patient and may cause suffer due to insufficient analgesia. Nevertheless, there are propositions to use organ donation euthanasia [26]. It is also presumed that in such case the process of death would be less connected with suffering because of applying of full anesthetic doses.

Euthanasia is prohibited in many countries in any version. Those countries who allow euthanasia (Switzerland, Netherlands, Belgium, Luxemburg, Canada, Australia, several states of the USA) have very different approaches to its regulation. Switzerland allows euthanasia for both residents and non-residents. There are also many strict conditions which should be fulfilled for the euthanasia to be applied, among them are the following: 1) incurable sickness or/ and unbearable suffering; 2 ) age of the patient (Netherland allows euthanasia from 12 years old with parental consent); 3) period of suffering or predicted period of life (6 months in Australia); 4) a few alternative doctors' points of view about termination of the sickness. Some countries allow both euthanasia and assisted suicide without medics (Belgium). In any case to evade human's right abuse it is worth to establish an obligatory participation of an independent side and notary or equally subsidiary documented consent of the patient and parents if needed.

Every person has the right to health not only for itself but either for his/her relatives health especially children, this right is connected with right to family autonomy. The persons' right to health of their relatives is reinforced in the legal norms of different countries, for example "weak" model for expressed consent for organ removal anticipates obligatory permission of such procedure by relatives of the deceased even if there is a notarized volition of the deceased on the donation of organs (United Kingdom, Japan and Lebanon) [27]. Surely, that almost all countries which have legalized system of expressed consent for organ removal anticipated "strong" version of consent, that means none of the relatives of the deceased person may change his/her volition to remove organs (Argentina, Australia, Denmark, Norway, the Philippines, Romania, Slovenia, Venezuela) [28].
But, what the legislation states about making decisions of application of an alternative therapeutic methods and measures when an adult person is out of consciousness? Legislative acts of most countries provide that adult people give consent to treatment by themselves if they are mentally capable. In case of some mental health conditions (schizophrenia, bipolar disorder, dementia, intoxication caused by alcohol misuse etc.) members of patient's family can make decisions concerning treatment even if mental health is diminished temporarily. When person is out of consciousness, such decisions can be made by members of patient's family or by physician when such decisions are urgent for life saving. The 'weak' place of relatives' right to family autonomy in most countries is an absence of legislative norms on obligation to inform relatives by hospital servicers about patient's health.

\section{CONCLUSIONS}

Human life, health and freedom are the highest democratic values. And it is of great importance to adopt legislative norms with the highest standards of protection of these rights. In our opinion, this research shows that restriction of patient's rights in meaning of forced medical interventions are never too necessary for social interest, except for some cases related to mentally disordered persons and proportional applying of liberty-limiting interventions due to pandemic threaten. Consent or disconsent to treatment and other medical interventions should be adhered for mentally competent adults under any circumstances. In case of controversial issues about interests of minors and mentally disordered adults when there is no mutual vision about their best interests between a physician and a guardian, the court has to solve the dispute. Next of kin has the right to consent instead of his relatives unless adult ones previously made a notarized or other authorized volition about definite health-care interventions.

\section{REFERENCES}

1. Declaration of Lisbon on the rights of the patient, adopted by the WMA, 1993. Available from: https://www.wma.net/policies-post/ wma-declaration-of-lisbon-on-the-rights-of-the-patient/ [reviewed: 2020.08.12].

2. European Charter of Patient's Rights, Rome, 2002. Available from: https://ec.europa.eu/health/ph_overview/co_operation/mobility/ docs/health_services_c0108_en.pdf [reviewed: 2020.08.10].

3. International Code of Medical Ethics, adopted by General Assembly of theWMA, 1949. Available from: https://www.wma.net/policies-post/ wma-international-code-of-medical-ethics/ [reviewed: 2020.08.12].

4. Convention on Human Rights and Biomedicine, Ovideo, 1997. Available from: https://www.academia.edu/457872/The_0viedo_ Convention_a_European_Legal_Framework_at_the_Intersection of_Human_Rights_and_Health_Law [reviewed: 2020.08.12].

5. Tsyvilnyi kodeks Ukrainy, 2003.01.16. [Civil Code of Ukraine] Available from: https://zakon.rada.gov.ua/laws/show/435-15\#Text (In Ukrainian) [reviewed: 2020.08.25].

6. Gostin L and Gostin K. A Broader Liberty: J. S. Mill, Paternalism and the Public's Health. Public Health. 2009; 123(3):14-21.

7. Nyamutata C. Do Civil Liberties Really Matter during the Coronavirus Disease (COVID-19). International Human Right's Laws Review. 2020; 9: 62-98. 
8. International Covenant on Civil and Political Rights, adopted by General Assembly of UN, 1966. Available from: https://www.ohchr.org/EN/ Professionallnterest/Pages/CCPR.aspx [reviewed: 2020.08.19].

9. Case of Zaichenko v. Ukraine, application no 45797/ judgement of 26 February 2015. Available from: http:/hudoc.echr.coe.int/ rus?i=001-166735. [reviewed: 2020.08.19].

10. Saya A, Brugnoli C, Piazzi G et al. Criteria, Procedures, and Future Prospects of Involuntary Treatment in Psychiatry Around the World: A Narrative Review. Front. Psychiatry. 2019; 10:271. doi: 10/3389/ fpsyt.2019.00271

11. Senegal K, Thys K, Vears D et al. Legal Approaches regarding HealthCare Decisions involving Minors: Implications for Next-Generation Sequencing. European Journal of Human Genetics. 2016; 24(11):1559-1564.

12. Ustawa 0 zawodach lekarza i lekarza dentysty, 1996.12.05. [Act on professions of doctor and dentist] (In Poland). Available from: http:// www.oil.org.pl/xml/oil/oil68/tematy/lek_lek_dent. [reviewed: 2020.08.07].

13. Iemelianenko V, Gornostay A, Ivantsova A. Reproductive Rights Violations: Forced Sterilization and Restriction of Voluntary Sterilization. Wiadomosci Lekarskie. 2019; 12:2536-2540.

14. Compulsory sterilization. Available from: https://wikimili.com/en/ Compulsory_sterilization [reviewed 2020.08.14].

15. Barboza D. China Suspends Family Planning Workers after Forced Abortion. The New York Times. 2012: 07.27.

16. Erdman J. Theorizing Time in Abortion Law and Human Rights. Health Human Rights. 2017; 19(1):29-40.

17. Convention for the Protection of Human Rights and Fundamental Freedoms ETS No 005 dated 04.11.1950. Available from: https://www. echr.coe.int/Documents/Convention_ENG.pdf [reviewed 2020.08.18].

18. Declaration of Oslo Statement on Therapeutic Abortion, adopted by WM0, 1970. Available from: http://ethics.iit.edu/ecodes/node/3929 [reviewed 2020.08.18].

19. Demidova L, Demidova E, Dudchenko A Vaccination against Infectious Diseases: International Standards of Patient's Rights. Wiadomosci Lekarskie. 2019; 12:2518-2523.

20. Donald N, Harmon S, Dube E et al. Mandatory Infant \& Childhood Immunization: Rationales, Issues and Knowledge Gaps. Vaccine. 2018; Vol. 36; 39:5811-5818. doi.org/10.1016/.

21. Aaby P, Ravn H, Roth A et al. Early diphtheria-tetanus-pertussis vaccination associated with higher female mortality and no difference in male mortality in a cohort of low birthweight children: an observational study within a randomised trial. Archives of Diseases in Childhood. 2012; 97:685-691.
22. Ley sobre trasplante de organos y materiales anatomicos en seres humanos. Gaseta 0ficial. \#4.497. Extraordinario, Caracas jueves 3 de diciembre de, 2017:79.

23. The Death Watch: Certifying Death Using Cardiac Criteria by Michael A. DeVita, MD, University of Pittsburg Medical Center, Pittsburg, Pa Prog. Transplant, 2001; 11(1):58-66.

24. Mental Capacity Act of UK 2005 Available from: https://www. legislation.gov.uk/ukpga/2005/9/contents [reviewed 2020.08.10].

25. Ronald E. Cranford What is a minimally conscious state? West Journal of Medicine. 2002; 176(2): 129-130.

26. Wilkinson D, Savuloscu J. Should we allow organ donation euthanasia? Alternatives for maximizing the number and quality of organs for transplantation. Bioethics. 2012; 26(1):32-48.

27. Vasilenko M, Zaporozhchenko A, Perezhniak B, Presumption of Consent in ECHR Practice and Legal Models for Organ Removal for Transplantation. Wiadomosci Lekarskie. 2019; 12: 2541-2546.

28. Price D. Legal and Ethical Aspects of Organ Transplantation. - Cambridge: Cambridge University Press, 2000:118.

\section{ORCID and contributionship:}

Natalia D. Kogut: 0000-0001-6990-8752 A, B.D

Serhii Y. Petriaiev: 0000-0002-8951-8601 C, E, F

\section{Conflict of interest:}

The Authors declare no conflict of interest

\section{CORRESPONDING AUTHOR Natalia D. Kogut}

National Technical University of Ukraine

"Igor Sikorsky Kyiv Polytechnic Institute",

Kyiv, Ukraine

tel: +380977517403

e-mail: kogut.nataly@gmail.com

Received: 01.09 .2020

Accepted: 30.11 .2020

A - Work concept and design, B - Data collection and analysis, C - Responsibility for statistical analysis, D-Writing the article, $\mathbf{E}$-Critical review, $\mathbf{F}$ - Final approval of the article 